\title{
Stent removal after transplantation: Ouch!
}

\author{
A Kumar, E Dale, S Hinchliffe, Y Marie, K Firth, S Curran, S Boyes. \\ Sheffield Kidney Institute, Northern General Hospital, Sheffield
}

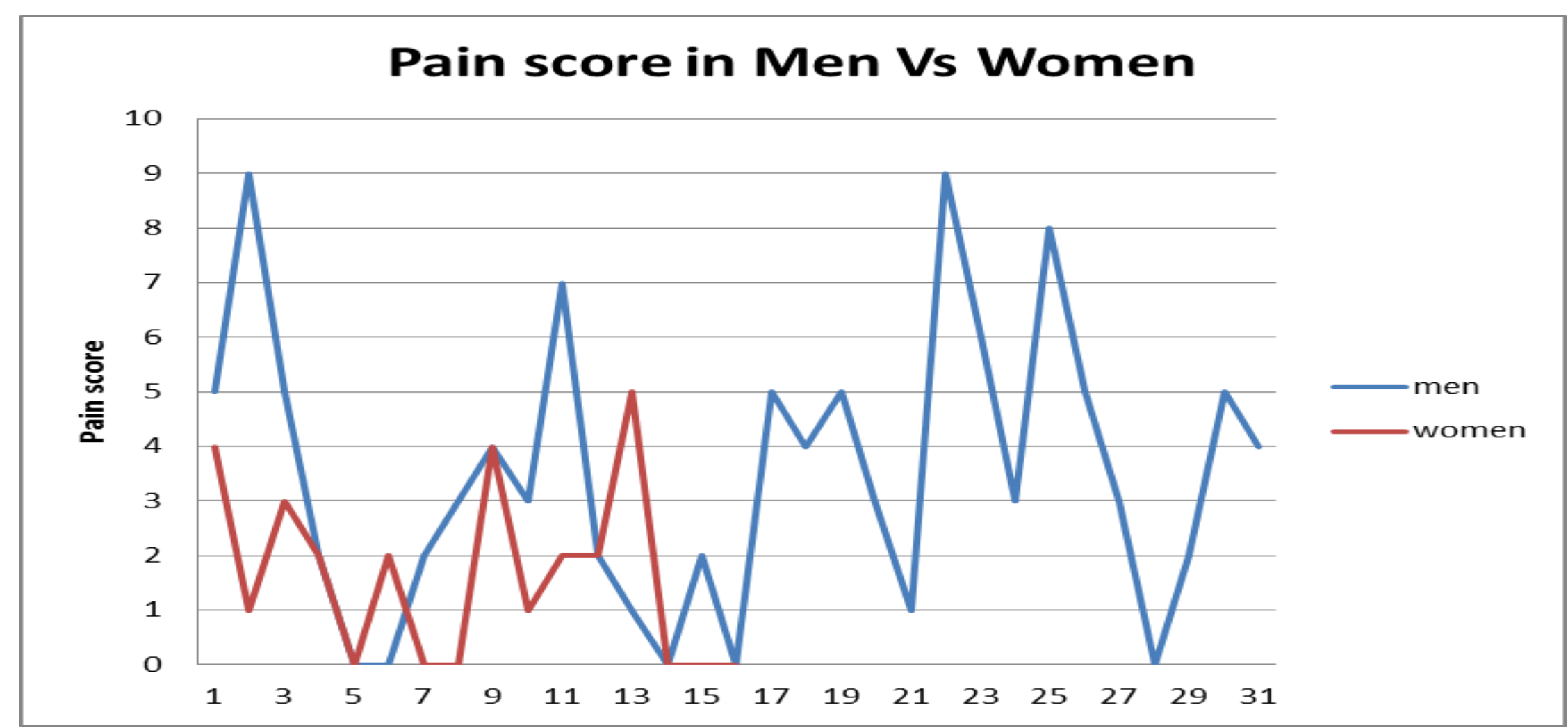

Introduction:

Results:

Ureteric stents are routinely placed during renal transplantation and require removal after 6-8 weeks. Removal procedure is often a source of considerable anxiety and pain. The severity of pain during stent removal is not well documented among transplant recipients.

\section{Aim:}

Find the intensity of pain during stent removal Gender difference in pain

Find the time interval for removal after transplantation

\section{Methods:}

A simple postal questionnaire was designed and sent to 103 patients. All patients who had renal transplantation within the last 18 months from Jan 2015 to June 2016 were included. They were asked to give a $0-10$ numeric pain intensity score where 10 was the worst possible pain and 0 being no pain.

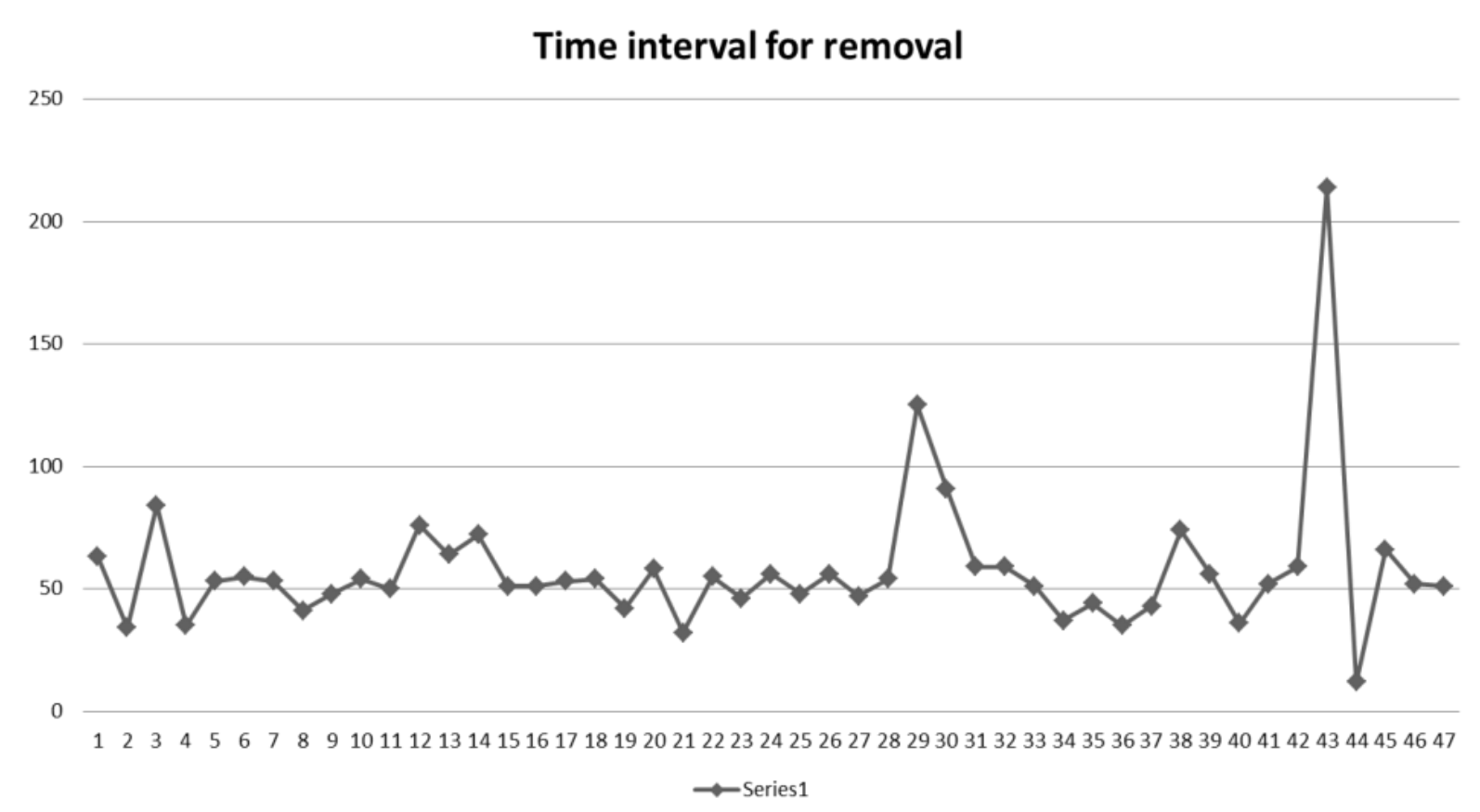

Calleary JG, Masood J, Van-Mallaerts R, Barua JM. Nitrous oxide inhalation to improve patient acceptance and reduce procedure related pain of flexible cystoscopy for men younger than 55 years. J Urol. 2007 Jul; 178(1):184-8

A Young, M Ismail, AG Papatsoris, JM Barua, JG Calleary, J Masood Entonox ${ }^{\circledR}$ inhalation to reduce pain in common diagnostic and therapeutic outpatient urological procedures: a review of the evidence. Ann R Coll Surg Engl 2012; 94: $8-11$.
52 responses were received. 5 patients were excluded due to the following ( 2 removal under spinal anaesthesia, 1 under general anaesthesia, 2 spontaneous passage)

Total included in analysis $=47,31$ men, 16 women. Median age 61 years (26-73).

Median time for removal of stent 53 days (12-214).

Median pain score $2(0-9) n=47$.

Median pain score in men was $3(0-9)$ and $1(0-5)$ in women.

18 men had pain score of 3 or $>3(58 \%)$ while 4 women had a pain score of 3 or $>3(25 \%)$

$47 \%$ overall had score of 3 or more

$58 \%$ of men had pain score of 3 or more but also had higher scores reaching up-to 9 in some cases.

\section{Discussion:}

Pain during stent removal is common and often severe in men. The patient experience appears to be unsatisfactory. Entonox, a self-administered mix of nitrous oxide and oxygen is used routinely for pain relief during short procedures. It is perhaps an underutilised analgesic and anxiolytic with minimal side effects. Rapid induction and recovery make it an ideal agent to use for stent removal. Stent removal is not invasive enough to justify the risk of complete anaesthesia but also too uncomfortable to be not taken seriously.

Based on this survey we intend to offer the use of Entonox during stent removal. 